\title{
Characterizations of precipitation behavior of Al-Mg-Si alloys under different heat treatments
}

\author{
Hui Li ${ }^{1,3}$, Jia-yi Wang ${ }^{2}$, *Hai-tao Jiang ${ }^{2}$, Zheng-feng Lü ${ }^{3}$, and Zhen-feng Zhu ${ }^{1}$ \\ 1. College of Engineering, Yantai Nanshan University, Yantai 265700, China; \\ 2. Institute of Engineering Technology, University of Science and Technology Beijing, Beijing 100083, China; \\ 3. National Engineering Research Center for Plastic Working of Aluminum Alloys, Shandong Nanshan Aluminum Co., Ltd., Yantai 265713, China
}

\begin{abstract}
The solidification-precipitation behavior of Al-Mg-Si multicomponent alloys has long been an absorbing topic. Experiments were carried out to analyze the precipitation behaviors of Al-Mg-Si alloys under different heat treatments. All specimens were homogenized at $570{ }^{\circ} \mathrm{C}$ for $8 \mathrm{~h}$, and then solution treated at $540{ }^{\circ} \mathrm{C}$ for 55 min. Subsequently, the specimens were age treated for different times at temperatures of $100{ }^{\circ} \mathrm{C}, 150{ }^{\circ} \mathrm{C}$ and $180{ }^{\circ} \mathrm{C}$, respectively. The experimental results show that the occurrence of dispersed free zones (DFZ) is caused by the uneven distribution of dispersed phase. During the aging process, pre- $\beta$ " phases form at the initial stage and an aging temperature of $100{ }^{\circ} \mathrm{C}$ is too low to complete the transformation of pre- $\beta^{\prime \prime}$ to $\beta^{\prime \prime}$. At $150{ }^{\circ} \mathrm{C}$, the precipitation sequence is concluded as SSSS-pre- $\beta$ " - pre $-\beta^{\prime \prime}+\beta^{\prime \prime}-\beta^{\prime \prime}-\beta^{\prime}-\beta$. Moreover, changes in sizes and densities of the pre- $\beta$ ", $\beta$ "and $\beta^{\prime}$ phases during the aging process has an important influence on the evolution of microhardness and electrical resistivity. The microhardness peak value of $150{ }^{\circ} \mathrm{C}$ is similar to that of $180^{\circ} \mathrm{C}$, which is $\sim 141 \mathrm{HV}$. While, at $100^{\circ} \mathrm{C}$, the microhardness increases slowly, and the attainable value is $127 \mathrm{HV}$ up to 19 days. When the aging temperature is $100^{\circ} \mathrm{C}$, the electrical resistivity has the highest average value. When the aging temperature exceeds $100^{\circ} \mathrm{C}$, with the occurrence and growth of $\beta^{\prime \prime}$ and $\beta^{\prime}$, the resistivity has a distinct decrease with prolonged aging time.
\end{abstract}

Key words: Al-Mg-Si alloy; heat treatment; precipitation behavior; electrical resistivity

CLC numbers: TG146.21 Document code: A Article ID: 1672-6421(2018)02-089-08

\begin{abstract}
A 1-Mg-Si alloys (6xxx) are widely used in construction and automotive industry because of their good physical and chemical properties ${ }^{[1,2]}$. The major alloying elements of $\mathrm{Mg}$ and $\mathrm{Si}$ in $\mathrm{Al}-\mathrm{Mg}-\mathrm{Si}$ alloys can result in precipitation strenghening through heat treatment. Therefore, heat treatment (homogenizing and aging treatment) is of great importance for Al-MgSi alloys. The solute redistribution during solidification leads to micro-segregation and formation of coarse intermetallic particles, which can significantly influence the mechanical properties of Al-Mg-Si alloys ${ }^{[3]}$. In order to decrease the micro-segregation and dissolve the micron-scale constituents, the as-cast specimens require a homogenization treatment to make the material suitable for subsequent processing. During the homogenization treatment, following microstructure envolutions will occur, such as the transformation of $\mathrm{Al}_{5} \mathrm{FeSi}$ intermetallics into $\mathrm{Al}_{12}(\mathrm{FeMn})_{3} \mathrm{Si}$, the solute redistribution around grain
\end{abstract}

\section{*Hai-tao Jiang}

Male, born in 1976, Ph.D., Associate Professor. His research interest mainly focuses on the development of non-ferrous metal materials. Up to date, he has published more than 100 papers in journals and conference proceedings. E-mail: 770526023@qq.com

Received: 2017-07-03; Accepted: 2018-01-10 boundaries and the dissolution of $\mathrm{Mg}_{2} \mathrm{Si}$ particles, $\mathrm{Al}-\mathrm{Fe}-$ $\mathrm{Si}$ and Al-Fe-Mn-Si phases, etc ${ }^{[4]}$.

$\mathrm{Al}-\mathrm{Mg}-\mathrm{Si}$ alloy is an aging hardenable alloy, with $\mathrm{Mg}$ and $\mathrm{Si}$ as major alloying elements ${ }^{[5]}$. The degree of age hardening is closely related to the type and content of precipitates, thus, it is vital to identify the precipitation process and evolution of precipitates. In general, the precipitation sequence in $\mathrm{Al}-\mathrm{Mg}-\mathrm{Si}$ alloys is generally accepted as SSSS-GP zones $-\beta^{\prime \prime}-\beta^{\prime}-\beta$, where SSSS is a super saturated solid solution, GP zones are Guinier Preston zones ${ }^{[6]}$. According to Murayama ${ }^{[7]}$, the GP zones are divided into GP-1 and GP-2 zones, which are called pre- $\beta^{\prime \prime}$ and $\beta^{\prime \prime}$, respectively. The pre- $\beta "$, with the base-centered monoclinic structure ${ }^{[2]}$, has the same structure as the most effective hardening phase $\beta^{\prime \prime}$. These two phases are fully coherent with the matrix. The semicoherent $\beta^{\prime[8]}$, with hexagonal structure, plays a minor role in the strengthening effect, while the incoherent equilibrium $\beta$ phase, with anti-fluorite structure, has no hardening effect ${ }^{[9]}$. Marioara ${ }^{[1]}$ reported that the precipitates exist steadily at lower temperatures and the precipitation sequence is different at different temperatures. Werinos ${ }^{[10]}$ proposed that long time natural aging from weeks to years retards artificial 
aging kinetics due to slower cluster dissolution kinetics. Considering the average $\mathrm{Mg} / \mathrm{Si}$ ratio of different precipitates ranged from about 0.5 to 2.0 , some researchers investigated alloys with a total high $\mathrm{Mg}+\mathrm{Si}$ content $(\sim 2 \mathrm{wt} . \%)$ and $\mathrm{Mg} / \mathrm{Si}$ ratios of $0.5,1$ and $2^{[11-14]}$. The results show that the $\mathrm{Mg} / \mathrm{Si} \approx 1$ alloy reaches the highest strength after approximate one week of natural aging. Gaffar M A, et al. investigated the relationship between electrical resistivity and precipitation of Al-MgSi alloys ${ }^{[15-18]}$. They found that the crystallographic defects, precipitates, impurities and their distribution significantly influence the electrical resistivity.

Above all, heat treatments play a dominant role in precipitation behavior of age-hardenable Al-Mg-Si alloys. In this paper, the effects of heat treatment on precipitation behavior and the relationship between microhardness and electrical resistivity were investigated. By various techniques, such as transmission electron microscope (TEM), differential scanning calorimetry (DSC) and resistivity measurement, the details on the precipitation sequence of pre- $\beta^{\prime \prime}, \beta^{\prime \prime}$ and $\beta^{\prime}$ and its relation to the microhardness and resistivity were explored. Furthermore, in order to investigate the precipitation behaviors under different heat treatments, the solidification and precipitation model were constructed.

\section{Experimental procedure}

Experimental Al-Mg-Si alloy (Al 97.50wt.\%, Mg 0.732wt.\%, Si 0.723 wt.\%, Mn 0.53wt.\%, Cr 0.16wt.\%, Fe 0.229wt.\%, Cu 0.073 wt. $\%$, Ti 0.05 wt. $\%$ ) was melted in a HD-003 high vacuum furnace, and ingots with sizes of $\Phi 30 \mathrm{~cm} \times 40 \mathrm{~cm}$ were cast in a metal mold. The $20 \mathrm{~cm} \times 20 \mathrm{~cm} \times 4 \mathrm{~cm}$ samples cut from ingots were homogenized at $570{ }^{\circ} \mathrm{C}$ for $8 \mathrm{~h}$ and then cooled in a GWL$\mathrm{LB}$ electric resistance furnace. The homogenizing samples were cut into $10 \times 10 \times 10 \mathrm{~mm}^{3}$ specimens, which were subjected to a solid solution treatment at $540{ }^{\circ} \mathrm{C}$ for $55 \mathrm{~min}$ and subsequently quenched in water at room temperature. The specimens were immediately aged in a GWL-LB electric resistance furnace at $100{ }^{\circ} \mathrm{C}, 150{ }^{\circ} \mathrm{C}$ and $180^{\circ} \mathrm{C}$ for $0.5 \mathrm{~h}$ to $\sim 20$ days.

Microstructure observations were carried out using a Leica DMIRM optical microscope (OM) and a Quanta 450FEG scanning electron microscope (SEM) operated at $20 \mathrm{kV}$ and equipped with a Thermo NS7 EDS-system. Both OM and SEM

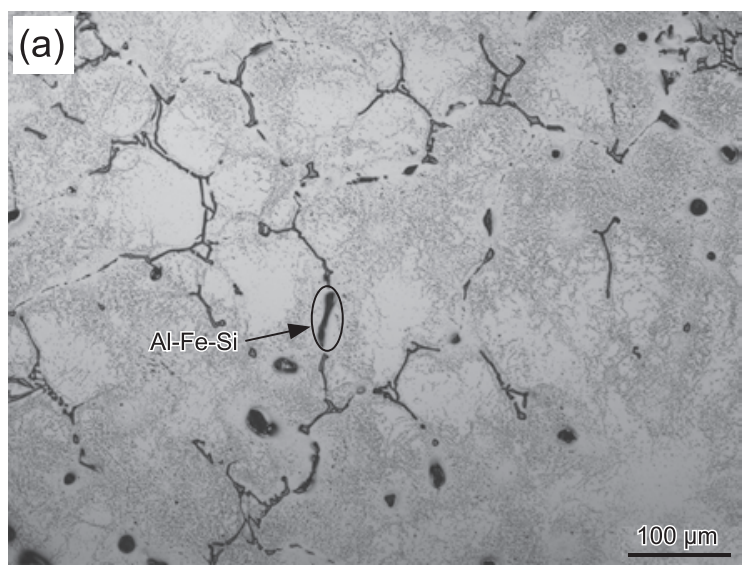

samples were mechanically polished and eroded with the mixed solution (10 ml HF, $15 \mathrm{ml} \mathrm{HCL}, 25 \mathrm{ml} \mathrm{HNO}_{3}, 95 \mathrm{ml} \mathrm{H} \mathrm{H}_{2} \mathrm{O}$ ). Transmission electron microscopy (TEM) and high resolution TEM (HRTEM) examinations were performed on a JEM-2010F electron transmission microscope at an acceleration voltage of $200 \mathrm{kV}$. Three millimeter diameter disks for TEM tests were punched out from the sample slices and mechanically ground to $30-50 \mu \mathrm{m}$ thickness, and then etched by double-jet polishing using a solution of $1000 \mathrm{ml}$ methanol and $500 \mathrm{ml} \mathrm{HNO}_{3}$ at a voltage of $12 \mathrm{~V}$ under $-30{ }^{\circ} \mathrm{C}$. In addition, some specimens were selected for TEM examinations and their corresponding microstructures were measured using Imagepro Plus software.

The Vickers microhardness $\left(\mathrm{kg} \cdot \mathrm{mm}^{-2}\right)$ was measured using a HV-1000 hardness tester at a load of $100 \mathrm{~g}$ and loading time of $15 \mathrm{~s}$. There were two samples for each aging treatment, and five hardness data were taken for each sample while the average values were used. Electrical resistivity after aging was performed using a SIGMATEST 2.089 instrument. Both the samples were mechanically ground up to P2000 SiC-paper with ethanol polish. DSC measurements were conducted on a DSC 204 Phoenix with nitrogen gas cooling using samples with 20 $\mathrm{mg}$ and $\mathrm{Al}$ pans. All DSC experiments were performed with a constant heating rate of $10{ }^{\circ} \mathrm{C} \cdot \mathrm{min}^{-1}$ from room temperature to $450{ }^{\circ} \mathrm{C}$ in argon atmosphere ${ }^{[19]}$.

\section{Results and discussion}

\subsection{Microstructure evolution during homogenizing treatment}

The as-cast and homogenized microstructures are shown in Fig. 1. The as-cast and homogenized microstructures consist of equiaxed grains with a measured average grain size of $150 \mu \mathrm{m}$ and $162 \mu \mathrm{m}$, respectively. As shown in Fig. 1(a), the Al-Fe-Si particles are visible along the grain boundaries. Furthermore, as can be seen from Fig. 1(b), there are plenty of dispersed phases $\left(\mathrm{Mg}_{2} \mathrm{Si}\right.$ and aluminide) inside the grains. More interestingly, after homogenizing treatment, some broad dispersed free zones (DFZ) induced by dispersed phases appear in neighbouring grains. Figures 1(c)-(f) show the SEM micrographs and the line scanning results. Obviously, the solutes $(\mathrm{Mg}, \mathrm{Fe})$ distribute more uniformly in Fig. 1(f) compared with Fig. 1(e). Moreover,

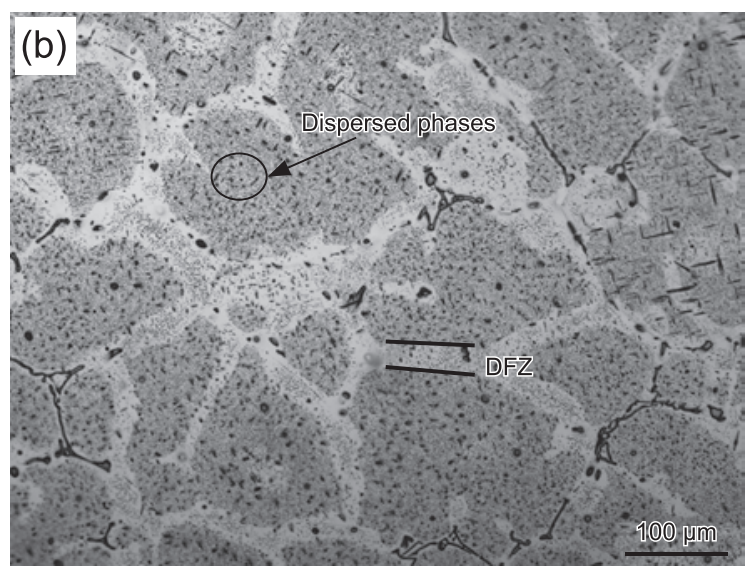



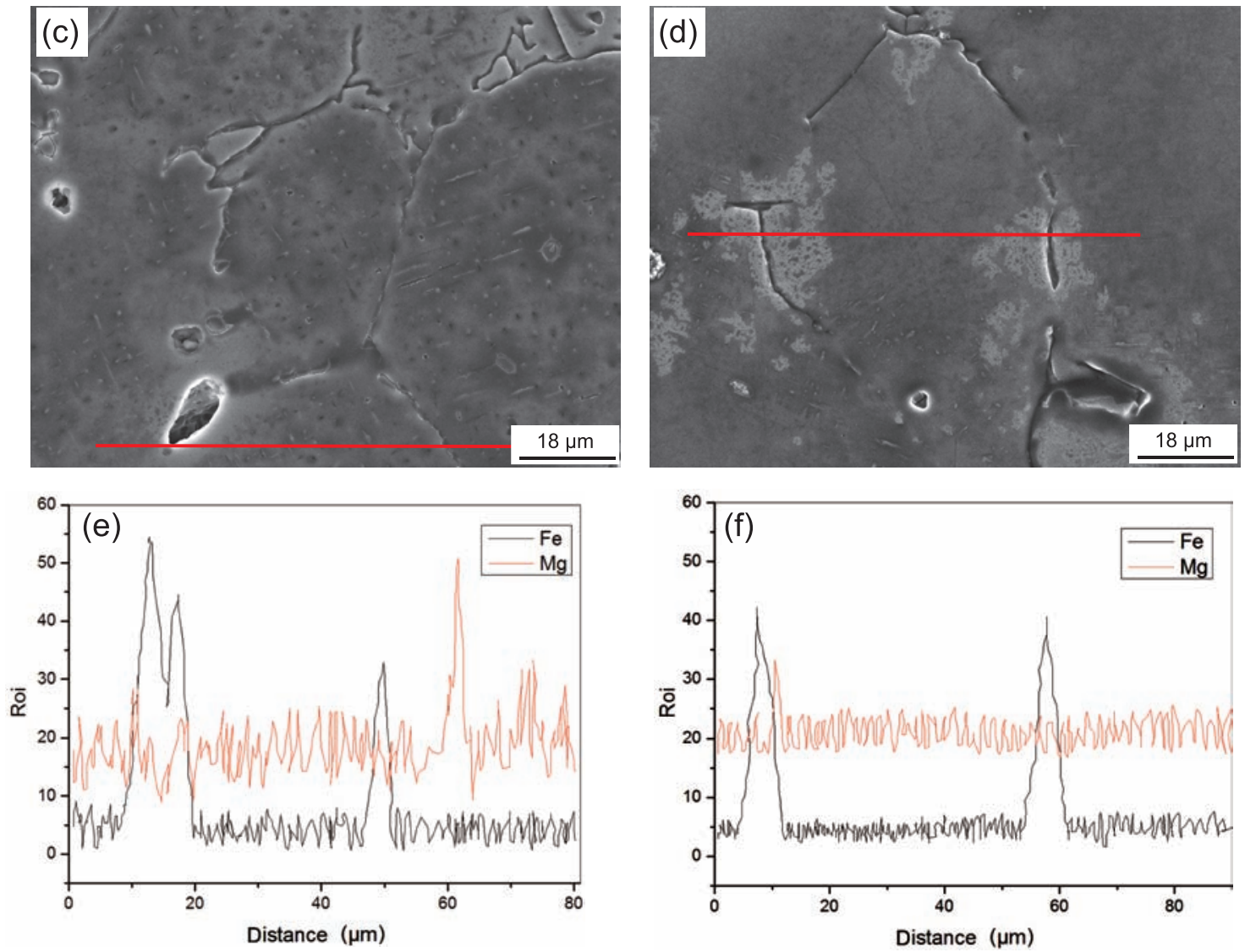

Fig. 1: Microstructures of specimens: (a) as-cast, OM; (b) homogenized, OM; (c) as-cast, SEM; (d) homogenized, SEM; (e and f) solute atom distributions in Fig. 1 (c and d)

it is clear that Al-Fe-Si particles are partially dissolved into the matrix due to the fluctuation of Fe element across grain boundaries. Figure 2 shows the Al-Fe-Si particles (red spot) around grain boundaries and their energy dispersive results. The composition of the Al-Fe-Si particle is $\mathrm{Al} 55.05 \mathrm{wt} . \%, \mathrm{Fe}$ 18.04 wt. $\%$ and Si 4.5 wt. $\%$ deriving from the point scanning results of EDS.

\subsection{Microhardness and electrical resistivity}

Microhardness curves of the specimens obtained under various heat treatments are shown in Fig. 3. The curves of the specimens aged at $150{ }^{\circ} \mathrm{C}$ and $180^{\circ} \mathrm{C}$ indicate similar features. As illustrated in Ref. ${ }^{[20,21]}$, the thermally activated phase transformations in $\mathrm{Al}-\mathrm{Mg}-\mathrm{Si}$ alloys are controlled by the diffusion of solute atoms. Thus, it is clear that the precipitation behavior of pecipitates are drastically different at different aging temperatures. At $150{ }^{\circ} \mathrm{C}$, the curve of microhardness exhibits a plateau from $8 \mathrm{~h}$ to 2 days during which there is little increase, and finally accompanied by a second increase to a maximum of approximately $141 \mathrm{HV}$. The $180{ }^{\circ} \mathrm{C}$ curve shows that the hardness of the material increases from $0.5 \mathrm{~h}$ to $2 \mathrm{~h}$ up to a value of $\sim 140 \mathrm{HV}$, followed by a period of fluctuation that lasts until 3 days and an increase until 6 days of aging time, and the microhardness experiences a dramatic drop at 14 days. Though the $100{ }^{\circ} \mathrm{C}$ curve is monotonic increasing, the
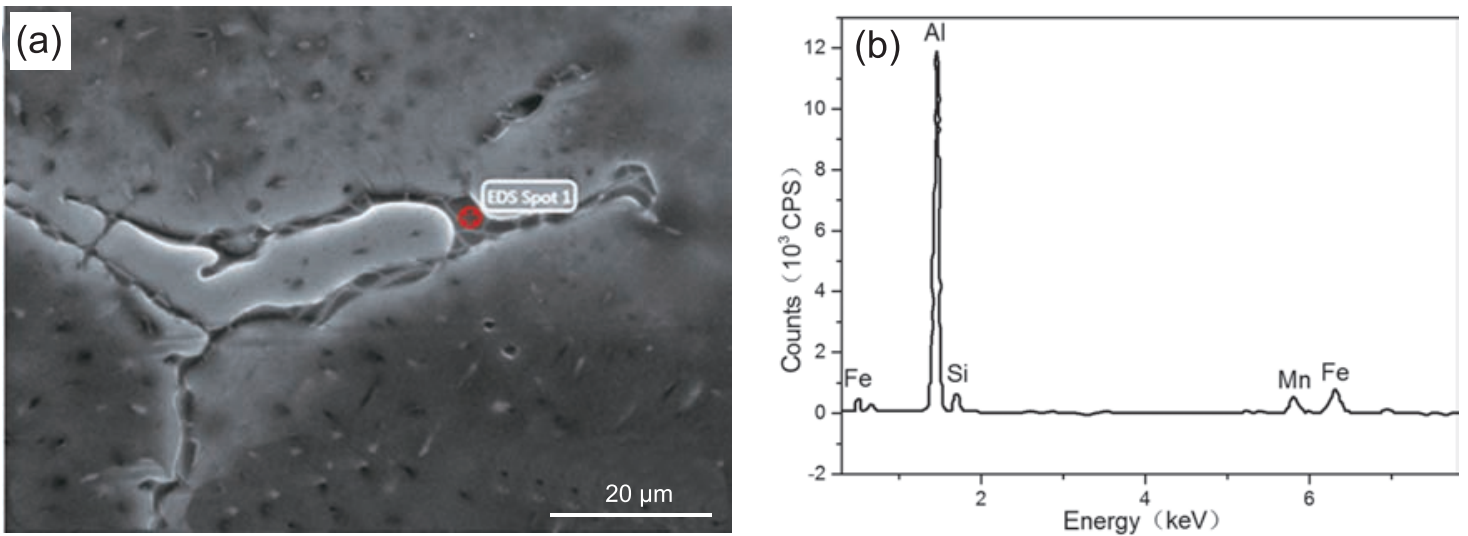

Fig. 2: Energy dispersive analysis of residual phases: (a) Al-Fe-(Mn)-Si phases around grain boundaries, (b) energy dispersive graph of Al-Fe-(Mn)-Si phases 


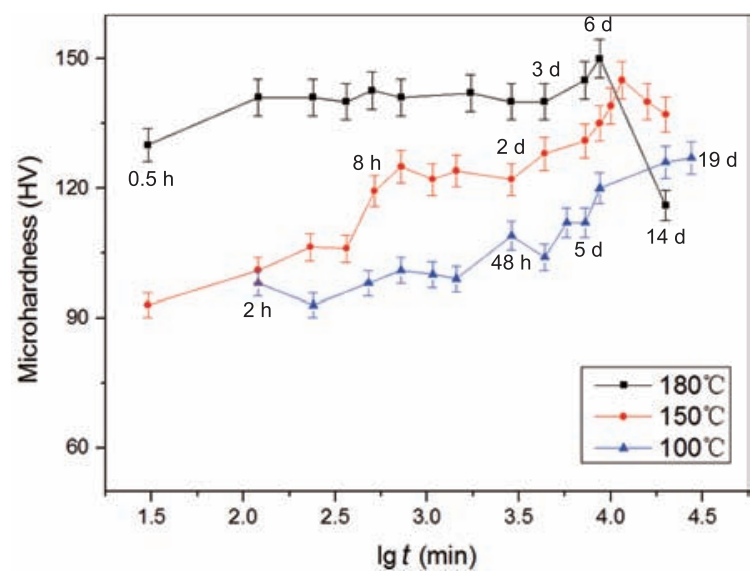

Fig. 3: Microhardness curves for different temperatures: $100^{\circ} \mathrm{C}, 150^{\circ} \mathrm{C}, 180^{\circ} \mathrm{C}$

microhardness increases slowly, and in this case the attainable value is $127 \mathrm{HV}$ up to 19 days, which is different from the curves of 150 and $180{ }^{\circ} \mathrm{C}$.

The electrical resistivity changes due to the aged microstructure also influence the microhardness. Figure 4 shows that the electrical resistivity of the alloy decreases with prolonged time at different aging temperatures. At the initial stage of aging $\left(100^{\circ} \mathrm{C}, 150{ }^{\circ} \mathrm{C}\right.$ and $\left.180{ }^{\circ} \mathrm{C}\right)$, the electrical resistivity sharply decreases. When the aging temperature is $100{ }^{\circ} \mathrm{C}$, the electrical resistivity exhibits minor fluctuations except for the initial stage, and has the highest average electrical

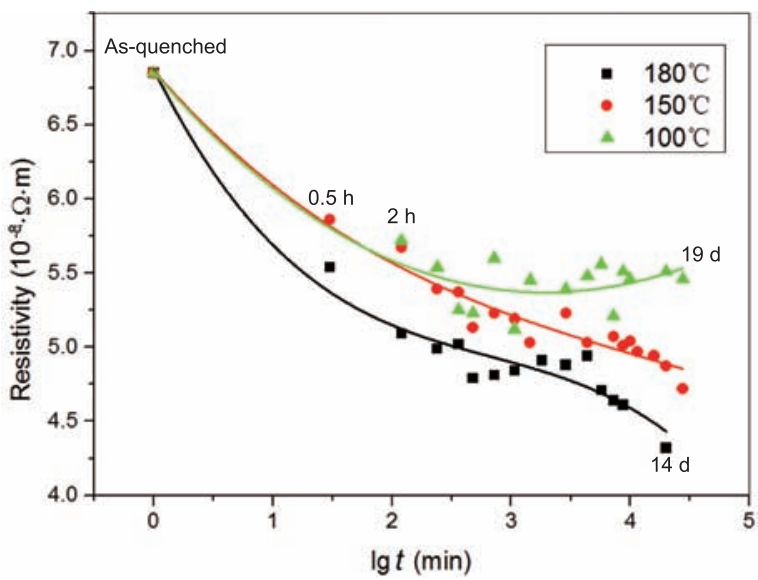

Fig. 4: Electrical resistivity values during aging processes at different temperatures

resistivity. When the aging temperature exceeds $100{ }^{\circ} \mathrm{C}$, the electrical resistivity has a distinct decrease with prolonged aging time. In summary, the electrical resistivity exhibits an opposite evolution trend compared with microhardness.

\subsection{Precipitation behavior during aging process}

Figure 5 shows electron microscope images [including bright field (BF) images and diffraction patterns] of specimens at various aging temperatures and times, and their corresponding microstructure parameters (density and size) are summarised in
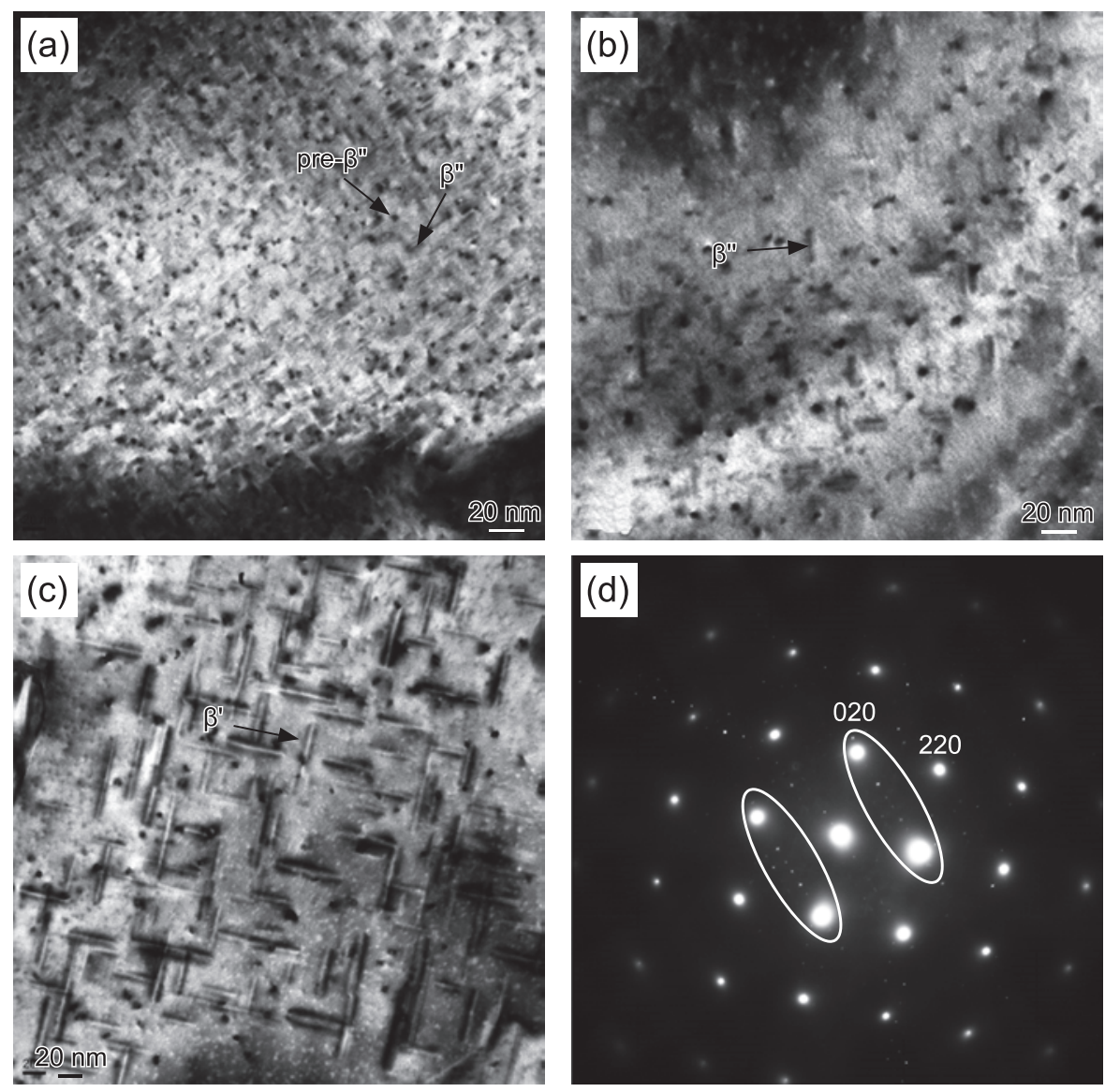

Fig. 5: Bright field images and diffraction patterns for specimens: (a) $150^{\circ} \mathrm{C}, 8 \mathrm{~h}$, (b) $150^{\circ} \mathrm{C}, 2$ days, (c) $180^{\circ} \mathrm{C}$, 14 days, (d) diffraction pattern of matrix and $\beta^{\prime}$ phase in (c). The viewing direction is $\langle 100>\mathrm{Al}$ 
Table 1 . During the early stages of $150{ }^{\circ} \mathrm{C}$, the pre- $\beta$ " phases can be found in the specimens aged for $8 \mathrm{~h}$, as shown in Fig. 5(a). The needle-like $\beta^{\prime \prime}$ in Fig. $5(\mathrm{~b})$, which was proposed as $\mathrm{Mg}_{5} \mathrm{Si}_{6}$, is observed ${ }^{[1,2]}$. The precipitates are aligned along $<100>\mathrm{Al}$, and are fully coherent along the needle axis. In general, needle-like $\beta^{\prime \prime}$ phases often develop at the beginning of the microhardness plateau together with a mixture of pre- $\beta^{\prime \prime}$ and $\beta^{\prime \prime}$. But over the plateau duration, the precipitates have already transformed to $\beta^{\prime \prime}$, thus coarse precipitates could be observed. Figure 5 (c) (aged at $180^{\circ} \mathrm{C}$ for 14 days) shows that a wealth of rod-like $\beta^{\prime}$ phases appear and the precipitates are obviously larger than those in Fig. 5(a) and (b), and the particle density in Fig. 5(c) is less than that in Fig. 5(a) and (b). The semi-coherent relation between $\beta^{\prime}$ and aluminum matrix can easily be identified by the diffraction pattern in Fig. 5(d).

Table 1: Density, size and type of precipitates

$\begin{array}{cccc}\text { Sample } & \text { Density }\left(\text { particles per } \mu \mathrm{m}^{2}\right) & \text { Length }(\mathrm{nm}) & \text { Precipitate type } \\ 150^{\circ} \mathrm{C} / 8 \mathrm{~h} & 150,000 \text { to } 200,000 & 9 & \text { pre- } \beta^{\prime \prime}+\beta^{\prime \prime} \\ 150^{\circ} \mathrm{C} / 2 \mathrm{~d} & 120,000 \text { to } 180,000 & 13 & \beta^{\prime \prime} \\ 180^{\circ} \mathrm{C} / 14 \mathrm{~d} & <100,000 & 25 & \beta^{\prime} \\ 100^{\circ} \mathrm{C} / 2 \mathrm{~h} & \text { Very low } & - & \text { pre- } \beta^{\prime \prime} \\ 100^{\circ} \mathrm{C} / 19 \mathrm{~d} & >400,000 & 4 & \text { pre- } \beta^{\prime \prime}\end{array}$

TEM images of $100^{\circ} \mathrm{C}$ ( $2 \mathrm{~h}, 19$ days $)$ in Fig. 6 demonstrate that a vast array of coherent pre- $\beta$ " (GP zones) phases appear in the matrix. There is a significant difference in size and number density (Table 1) of the fine particles in the matrix comparing with Fig. 5. However, there is no evidence that $\beta^{\prime \prime}$ can nucleate and grow at $100{ }^{\circ} \mathrm{C}$, even at the aging time up to 19 days. As shown in Fig. 6(b), the selected area electron diffraction (SAED) patterns show neither extra reflection nor diffuse scattering. HRTEM was carried out to get further information about the structure of the GP zones. The high resolution micrograph in Fig. 6(c) shows a GP zone embedded in the matrix aligned along [001] axis of the matrix. The fast fourier transformation (FFT) and its sketch in Fig. 6(d) illustrates that the GP zones are coherent with the matrix.
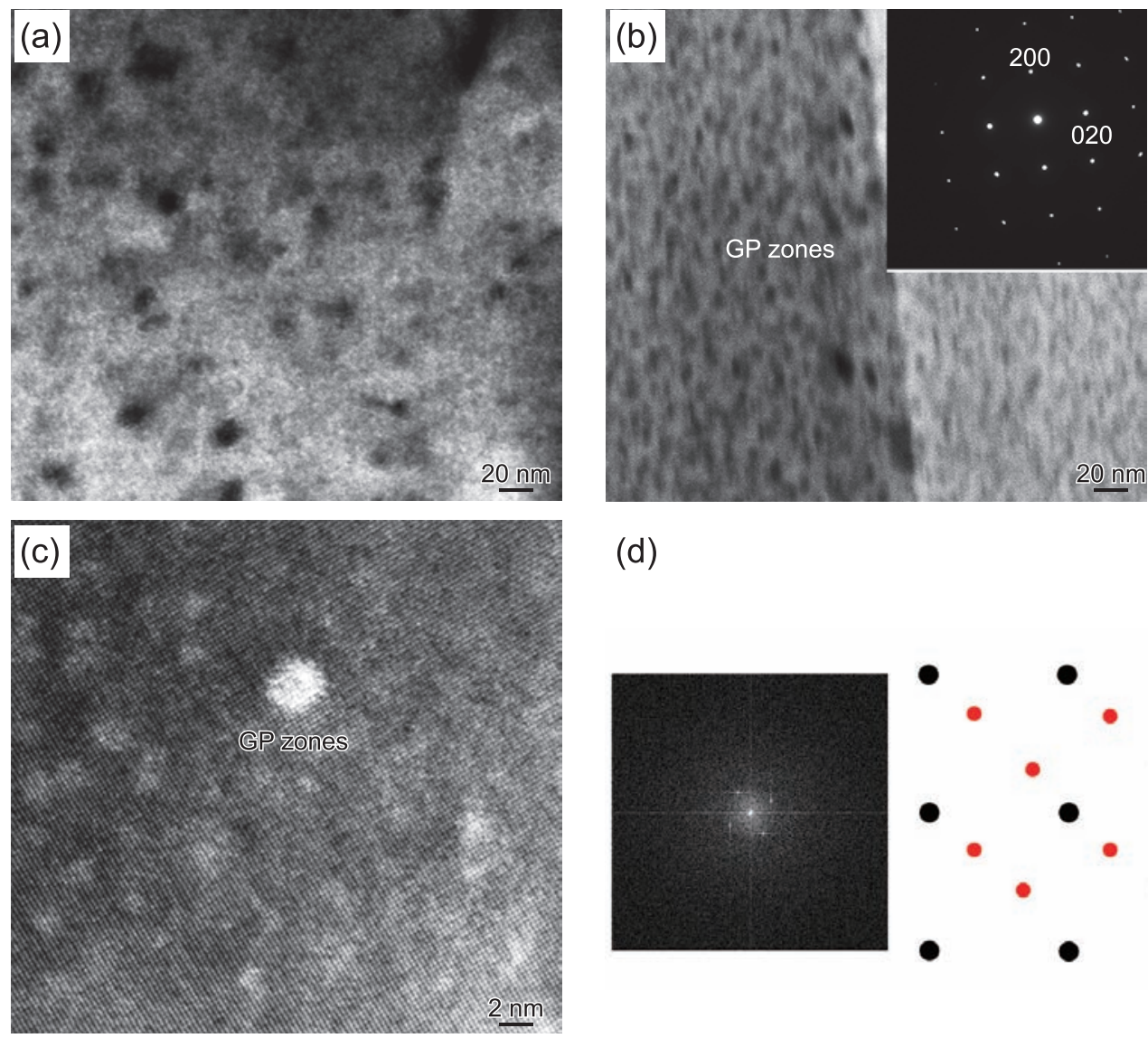

(d)

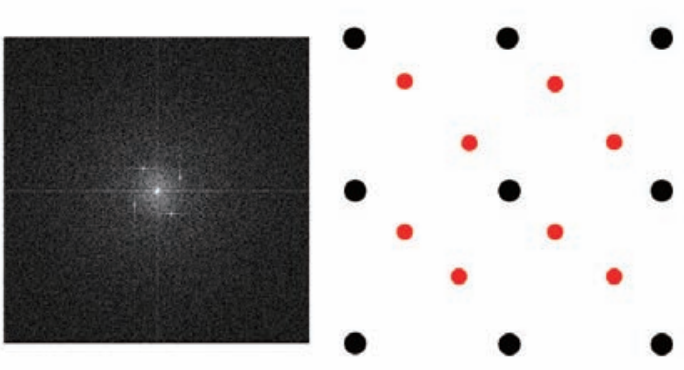

Fig. 6: TEM images of specimens: (a) $100^{\circ} \mathrm{C}, 2 \mathrm{~h}$, (b) $100^{\circ} \mathrm{C}, 19$ days, (c) GP zone embedded in matrix using [001] zone axis of matrix, (d) fast fourier transformation (FFT) of GP zone in (c) and sketch of FFT, the large black spots are matrix reflections, the small red spots are GP zone super lattice reflections. The viewing direction is $\langle 100>\mathrm{Al}$ 


\subsection{Discussion}

All the results presented above give a picture of the evolution of precipitates during heat treatments. It can be seen from Fig. 1 that a large number of dispersed phases appear after homogenizing treatment. This can be explained by the solute atom concentration at the solid-liquid interface. In view of the structure model ${ }^{[22]}$ and interaction between particles and solidliquid interface ${ }^{[23]}$, the precipitation behavior model around grain boundaries is constructed as shown in Fig. 7. In Fig. 7(a), there is an obvious composition fluctuation caused by large amounts of solute atoms ( $\mathrm{Fe}, \mathrm{Si}$ etc.) gathering at the frontier of solid-liquid interface of alloy matrix, so Al-Fe-Si phases inclined to form here. Meanwhile, the grain boundaries and crystal defects in the matrix more easily provide nucleation sites.
This is attributed to the decrease of defect free energy caused by nucleation which can surmount the nucleation barrier. Followed by the heterogeneous nucleation along grain boundaries, the Al-Fe-Si particles grow up persistently, which leads to a large amount of consumption of alloy elements. Moreover, the occurrence of DFZ is attributed to uneven distribution of dispersed phases which could diminish to some extent via adjusting solution processes. In Fig. 7(a) and Fig. 7(b), it can be deduced from heterogeneous nucleation and growth behavior that there exists a mass of element deficiency zones around grain boundaries. The absence of precipitates [Fig. 7(c)] adjacent to grain boundaries clearly illustrates the precipitation law of precipitates caused by element consumptions around grain boundaries.

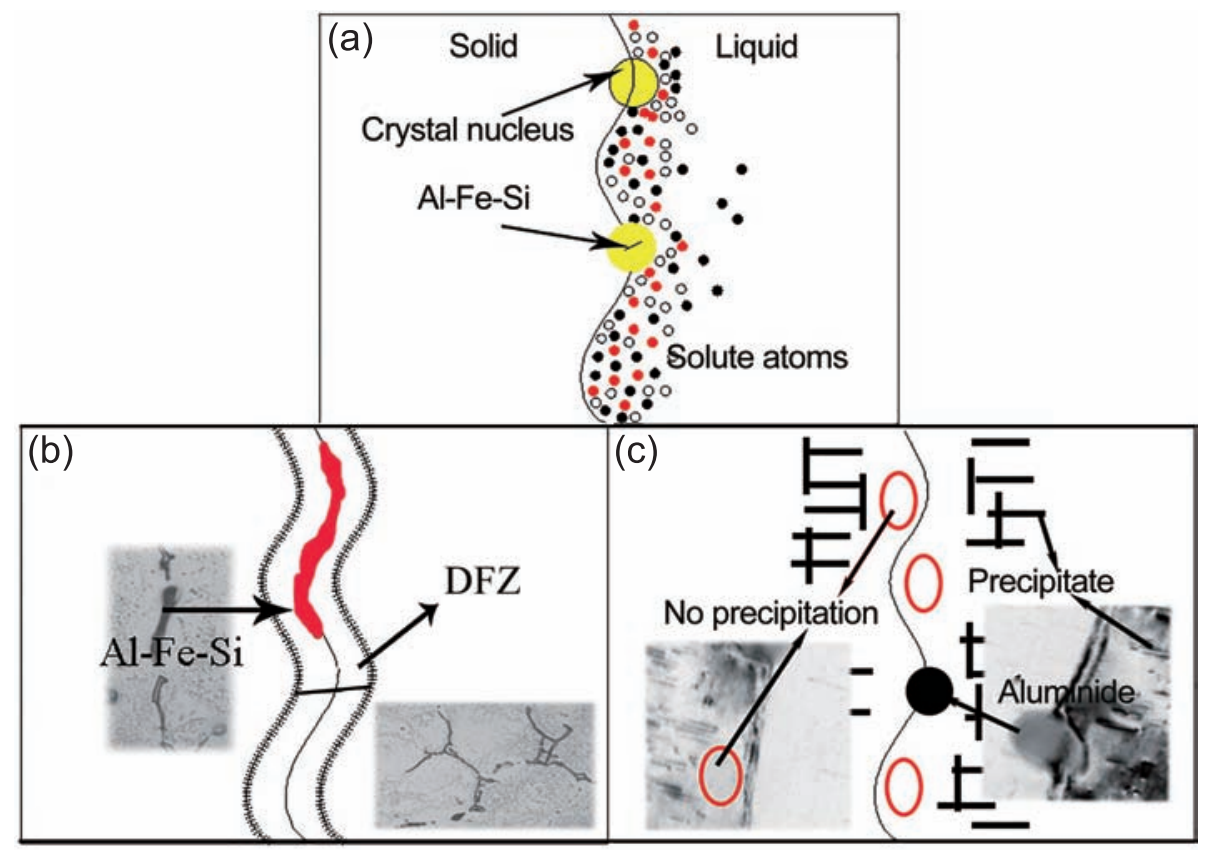

Fig. 7: Precipitation behavior model around grain boundaries: (a) solidification, (b) homogenization, (c) aging

In addition, Al-Fe-Si particles appear occasionally around the grain boundaries, and the artificial aging has no influence on these particles due to high melting temperature $\left(>580^{\circ} \mathrm{C}\right)$, which is in good agreement with the findings of Kumar ${ }^{[24]}$.

The microhardness curves and its evolution can be attributed to microstructure evolution and phase transformations. It is generally accepted that a lot of non-equilibrium quenched-in vacancies ${ }^{[13]}$ exist in the matrix after solid solution treatment at $540{ }^{\circ} \mathrm{C}$. During aging process at $100{ }^{\circ} \mathrm{C}$, only pre- $\beta$ " form, indicating that the temperature is too low to form $\beta^{\prime \prime}$ phases and that the pre- $\beta^{\prime \prime}$ can maintain long-term stability at this temperature, which is in agreement with the results of Marioara ${ }^{[1]}$. However, the nucleation and coarsening of pre- $\beta$ " precipitates lead to a slow increase of microhardness. During the aging process, the GP zones grow due to the Ostwald ripening ${ }^{[25]}$, which means that the density is decreasing and the morphology is coarsening. For the $150{ }^{\circ} \mathrm{C}$ curves, the microhardness plateau maintains from $8 \mathrm{~h}$ to 2 days, and during this period, the transformation from pre- $\beta$ " to $\beta$ " happens. It shoud be noted, however, that the long durations of microhardness plateau are possibly interpreted as the dynamic equilibration between the decrease in number density and growth in particle size of pre- $\beta$ " and $\beta^{\prime \prime}$. Data shown in Fig. 8 demonstrate a cluster dissolution trace with a broad endothermic peak and the formation of a $\beta^{\prime \prime}$ double peak. The first peak is attributed to needle-like $\beta^{\prime \prime}$ that evolve from coarse clusters and the second peak to the fine needle-like $\beta^{\prime \prime}$ derived from newly available solute atoms after the dissolution of unstable clusters. From the above analysis, and combined with the TEM and DSC results of $150{ }^{\circ} \mathrm{C}$, the precipitation sequence is concluded as SSSS-pre- $\beta^{\prime \prime}$-pre$\beta^{\prime \prime}+\beta^{\prime \prime}-\beta^{\prime \prime}-\beta^{\prime}-\beta$. The same precipitation sequence may present at $180{ }^{\circ} \mathrm{C}$, however, the absence of a microhardness plateau in comparison with $150{ }^{\circ} \mathrm{C}$ can be attributed to the accelerative artificial aging kinetics caused by the inferior stabilities of pre- $\beta$ ${ }^{\prime \prime}$ at the temperature of $180^{\circ} \mathrm{C}$.

Unlike the inferior hardening effect at the condition of 


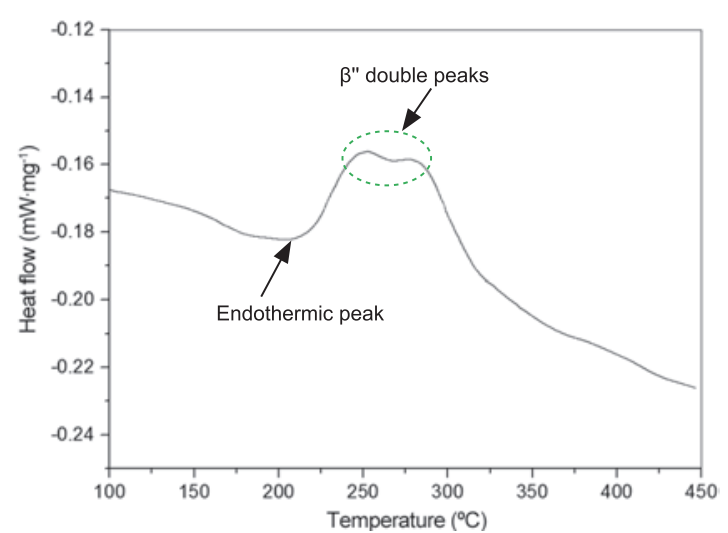

Fig. 8: DSC measurement of $150^{\circ} \mathrm{C}$ aged specimen

low aging temperatures and short aging time, the hardening strengthening at high temperatures and prolonged time is due to that the precipitates resulting from high temperatures and prolonged time are less coherent with the matrix even the number density decreases with the extension of temperature and time ${ }^{[1,2,26]}$. However, it can be concluded from Fig. 5(c) that the precipitation of rod-like $\beta^{\prime}$ phases reduces the distortion energy which leads to the reduction of microhardness. Meanwhile, the dramatically dropped particle density and coarsening of precipitates also make contributions to the microhardness reduction. The pre- $\beta$ " phases can exist at about $180{ }^{\circ} \mathrm{C}$ for a certain time ${ }^{[2]}$. This accounts for the initial increase in microhardness for $150{ }^{\circ} \mathrm{C}$ and $180{ }^{\circ} \mathrm{C}$ curves. The rapidly reachable peak microhardness at $180^{\circ} \mathrm{C}$ is due to fast formation of plenty of coherent $\beta^{\prime \prime}$ phases, and then the $\beta^{\prime \prime}$ phases transformed to semi-coherent $\beta^{\prime}$ phases, resulting in severe microhardness decrease after 6 days.

Generally, the electrical resistivity is effected by a complex interaction of various scattering centers including vacancies, grain boundaries, dislocations, clusters and precipitates ${ }^{[27,28]}$. The solution specimens before aging having the highest resistivity are due to the scattering function of quenched-in vacancies. Moreover, the smooth value fluctuation at $100^{\circ} \mathrm{C}$ can be explained by the fierce scattering function of pre- $\beta$ " phases, which indirectly demonstrates that pre- $\beta^{\prime \prime}$ phases exist in the matrix for a long period. In contrast, the changes in $150{ }^{\circ} \mathrm{C}$ and $180^{\circ} \mathrm{C}$ indicate that precipitates of $\beta^{\prime \prime}$ and $\beta^{\prime}$ dominate the whole aging process except for the clusters and pre- $\beta$ " dominates initial stages. As shown in Table 1 and Fig. 4, in comparison of electrical resistivity variations of $100^{\circ} \mathrm{C}, 150{ }^{\circ} \mathrm{C}$ and $180^{\circ} \mathrm{C}$, the electrical resistivity is more sensitive to number density of precipitates. Furthermore, though the number density of precipitates is similar at $150{ }^{\circ} \mathrm{C}$ and $180^{\circ} \mathrm{C}$ (Table 1 ), the difference of electrical resistivity between $150{ }^{\circ} \mathrm{C}$ and $180{ }^{\circ} \mathrm{C}$ in Fig. 4 is interpretable with the strong static recovery at a higher aging temperature $\left(180{ }^{\circ} \mathrm{C}\right)$, which results in the disappearance of crystal defects such as vacancies and dislocation, etc.

\section{Conclusions}

(1) Al-Fe-Si particles originated from non-equilibrium solidification are oriented along the grain boundaries. This situation is caused by the heterogeneous nucleation and solute atom concentration in the solid-liquid interface. The DFZ caused by uneven distribution of dispersed phases appears during the process of homogenizing treatment.

(2) During aging processes, pre- $\beta^{\prime \prime}$ phases form at the initial stage. Aging at $100{ }^{\circ} \mathrm{C}$ only induces a type of microstructure composed of fine distributions of pre- $\beta$ " phases up to 19 days. The microhardness peak value of $150{ }^{\circ} \mathrm{C}$ is similar to that of $180^{\circ} \mathrm{C}$, which is $\sim 141 \mathrm{HV}$. While, at $100{ }^{\circ} \mathrm{C}$, the microhardness increases slowly, and the attainable value is $127 \mathrm{HV}$ up to 19 days. At $150{ }^{\circ} \mathrm{C}$, the precipitation sequence is concluded as SSSS-pre- $\beta$ "-pre- $\beta "+\beta^{\prime \prime}-\beta^{\prime \prime}-\beta^{\prime}-\beta$.

(3) The evolution of precipitates has an important influence on electrical resistivity, which is more sensitive to number density of precipitates. When the aging temperature exceeds $100{ }^{\circ} \mathrm{C}$, with the occurrence and growth of $\beta^{\prime \prime}$ and $\beta^{\prime}$, the resistivity has a distinct decrease with prolonged aging time.

\section{References}

[1] Marioara C D, Andersen S J, Jansen J, et al. The influence of temperature and storage time at RT on nucleation of the $\beta$ " phase in a 6082 Al-Mg-Si alloy. Acta. Mater., 2003, 51(3): 789-796.

[2] Marioara C D, Andersen S J, Jansen J, et al. Atomic model for GP-zones in a 6082 Al-Mg-Si system. Acta. Mater., 2001, 49(2): 321-328.

[3] Totik $Y$, Gavgali M. The effect of homogenization treatment on the hot workability between the surface and the center of AA 2014 ingots. Mater. Charact., 2002, 49(3): 261-268.

[4] Mrówka-Nowotnik G, Sieniawski J. Influence of heat treatment on the microstructure and mechanical properties of 6005 and 6082 aluminium alloys. J. Mater. Process. Tech., 2005, 162: 367-372.

[5] Kumar N, Jayaganthan R, Brokmeier H G. Effect of deformation temperature on precipitation, microstructural evolution, mechanical and corrosion behavior of $6082 \mathrm{Al}$ alloy. Transactions of Nonferrous Metals Society of China, 2017, 27(3): 475-492.

[6] Chakrabarti D J, Laughlin D E. Phase relations and precipitation in Al-Mg-Si alloys with $\mathrm{Cu}$ additions. Prog. Mater. Sci., 2004, 49(3): 389-410.

[7] Murayama M, Hono K, Saga M, et al. Atom probe studies on the early stages of precipitation in Al-Mg-Si alloys. Mater. Sci. Eng., A, 1998, 250(1): 127-132.

[8] Andersen S J, Zandbergen H W, Jansen J, et al. The crystal structure of the $\beta^{\prime \prime}$ phase in Al-Mg-Si alloys. Acta Mater., 1998, 46(9): 3283-3298.

[9] Ravi C, Wolverton C. First-principles study of crystal structure and stability of Al-Mg-Si-(Cu) precipitates. Acta Mater., 2004, 52(14): 4213-4227.

[10] Werinos M, Antrekowitsch H, Ebner T, et al. Hardening of Al-MgSi alloys: Effect of trace elements and prolonged natural aging. Mater. Des., 2016, 107: 257-268.

[11] Zandbergen M W, Xu Q, Cerezo A, et al. Study of precipitation in Al-Mg-Si alloys by Atom Probe Tomography I. Microstructural changes as a function of ageing temperature. Acta Materialia, 2015, 101: 136-148.

[12] Serizawa A, Hirosawa S, Sato T. Three-dimensional atom probe characterization of nanoclusters responsible for multistep aging behavior of an Al-Mg-Si alloy. Metall. Mater. Trans. A, 2008, 39(2): 243-251.

[13] Torsæter M, Hasting H S, Lefebvre W, et al. The influence of composition and natural aging on clustering during preaging in 
Al-Mg-Si alloys. J. Appl. Phys., 2010, 108(7): 073527.

[14] Cao L, Rometsch P A, Couper M J. Effect of pre-ageing and natural ageing on the paint bake response of alloy AA6181A. Mater. Sci. Eng. A, 2013, 571: 77-82.

[15] Gaffar M A, Gaber A, Mostafa M S, et al. The effect of Cu addition on the thermoelectric power and electrical resistivity of Al-Mg-Si balanced alloy: A correlation study. Mater. Sci. Eng., A, 2007, 465(1): 274-282.

[16] Seyedrezai H, Grebennikov D, Mascher P, et al. Study of the early stages of clustering in Al-Mg-Si alloys using the electrical resistivity measurements. Mater. Sci. Eng. A, 2009, 525(1): 186191.

[17] Matsumoto K, Komatsu S, Ikeda M, et al. Quantification of volume fraction of precipitates in an aged Al-1.0 mass $\% \mathrm{Mg}_{2} \mathrm{Si}$ alloy. Mater. Trans., 2000, 41(10): 1275-1281.

[18] Raeisinia B, Poole W J, Lloyd D J. Examination of precipitation in the aluminum alloy AA6111 using electrical resistivity measurements. Mater. Sci. Eng., A, 2006, 420(1): 245-249.

[19] Hu X P, Zhou J X, Zhang X Z, et al. Characterization and kinetic modeling of secondary phases in squeeze cast $\mathrm{Al}$ alloy $\mathrm{A} 380$ by DSC thermal analysis. China Foundry, 2017, 14(2): 98-107.

[20] Gaber A, Gaffar M A, Mostafa M S, et al. Precipitation kinetics of Al-1.12Mg2Si-0.35Si and Al-1.07 $\mathrm{Mg}_{2} \mathrm{Si}-0.33 \mathrm{Cu}$ alloys. J Alloys Comd., 2007, 429(1): 167-175.
[21] Daoudi M I, Triki A, Redjaimia A. DSC study of the kinetic parameters of the metastable phases formation during nonisothermal annealing of an Al-Si-Mg alloy. J. Therm. Anal. Calorim., 2011, 104(2): 627-633.

[22] Kumar M, Poletti C, Degischer H P. Precipitation kinetics in warm forming of AW-7020 alloy. Mater. Sci. Eng., A, 2013, 561: 362-370.

[23] Mrotzek M, Nembach E. Ostwald ripening of precipitates during two successive heat treatments performed at different temperatures. Acta Mater., 2008, 56(1): 150-154.

[24] Cui Lixin, Liu Zhen-xing, Zhao Xiao-guang, et al. Precipitation of metastable phases and its effect on electrical resistivity of Al-0.96 $\mathrm{Mg}_{2} \mathrm{Si}$ alloy during aging. Trans. Nonferrous Met. Soc. China, 2014, 24(7): 2266-2274.

[25] Fickett F R. A review of resistive mechanisms in aluminum. Cryogenics, 1971, 11(5): 349-367.

[26] Raeisinia B, Poole W J. Electrical resistivity measurements: a sensitive tool for studying aluminium alloys. Trans Tech Publications, 2006, 519: 1391-1396.

[27] Panseri C, Federighi T. A resistometric study of precipitation in an aluminium-1.4 percent $\mathrm{Mg}_{2} \mathrm{Si}$ alloy. Inst Metals J, 1966, 94(3): 99-107.

[28] Lippmann S, Jung I H, Paliwal M, et al. Modelling temperature and concentration dependent solid/liquid interfacial energies. Philosophical Magazine, 2016, 96(1): 1-14.

This work was financially supported by the Natural Science Foundation of Shandong Province (ZR2016EMQ11) and the Major Research and Development Program of Shandong Province (2017GGX20119), China. 